\title{
Flushing Enhancement With Vibration and Pulsed Current in Electrochemical Machining
}

\section{Zhujian Feng', Jesus Manuel Orona-Hinojos², Pedro Perez-Villanueva ${ }^{2}$, Paul Lomeli ${ }^{3}$, and Wayne Nguyen Hung'}

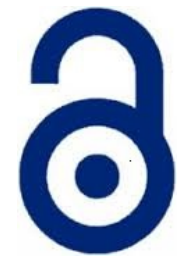

Received: 16 July 2017

Accepted: 02 October 2017

Published: 10 December 2017

Publisher: Deer Hill Publications

(c) 2017 The Author(s)

Creative Commons: CC BY 4.0

\begin{abstract}
This research aims to understand the flushing of by-products in electrochemical machining (ECM) by modeling and experimentally verifying mechanism of particle transport in inter-electrode gap under low frequency vibration. A series of hole were drilled on steel plates to evaluate the effect of vibration on material removal rate and hole quality. Infinite focus optical technique was used to capture and analyze the three-dimensional images of ECM'ed features. Experimental results showed that maximum machining depth and minimum taper angle can be achieved when vibrating the workpiece at $40 \mathrm{~Hz}$ and $10 \mu \mathrm{m}$ amplitude. Simulation results showed that the highest average flushing speed of $0.4 \mathrm{~m} / \mathrm{s}$ was obtained at this vibration frequency and amplitude. Machining depth and material removal rate had a positive correlation with the average flushing speed. Sharper ECM'ed profile is obtained since the taper angle is favorably reduced at high average flushing speed.
\end{abstract}

Keywords. Electrochemical machining, Low frequency vibration, Pulsed current.

\begin{tabular}{ll}
\multicolumn{1}{c}{ NOMENCLATURE } \\
\hline$A$ & Electrode area $\left(\mathrm{mm}^{2}\right)$ \\
$A_{o}$ & Initial gap between particle center and workpiece $(\mu \mathrm{m})$ \\
$A_{v}$ & Vibration amplitude $(\mu \mathrm{m})$ \\
$B$ & Constant equals to $\mathrm{A}_{v} \mathrm{f}^{2}$ \\
$C$ & Specific removal rate of workpiece $\left(\mathrm{mm}^{3} / \mathrm{A} / \mathrm{s}\right)$ \\
$\mathrm{CBN}$ & Cubic boron nitride \\
$d$ & Workpiece density $\left(\mathrm{g} / \mathrm{cm}^{3}\right)$ \\
$d_{g}$ & Gap between particle center and workpiece \\
$D_{1,} D_{2}$ & Hole diameters at levels $1,2(\mathrm{~mm})$ \\
$\mathrm{DC}$ & Direct current \\
$E$ & Applied voltage $(\mathrm{V})$ \\
$\mathrm{ECM}$ & Electro-chemical machining \\
$\mathrm{EDM}$ & Electro-discharging machining \\
$f$ & Vibration frequency $(\mathrm{Hz})$ \\
$F$ & Faraday constant $=96500 \mathrm{Coulomb} / \mathrm{mole}$ \\
$F_{b}$ & Buoyance force $(\mathrm{N})$ \\
$F_{d}$ & Drag force $(\mathrm{N})$ \\
$F_{r}$ & Total force along radial direction $(\mathrm{N})$ \\
$g$ & Inter-electrode gape (mm) \\
$G$ & Gravity force $(\mathrm{N})$ \\
$h$ & Height between level 1 and level 2 (mm) \\
$\mathrm{HSLA}$ & High strength low alloy \\
$I$ & Current in ECM operation $(\mathrm{A})$ \\
\hline
\end{tabular}

Z. Feng', J. M. Orona-Hinojos ${ }^{2}$, P. Perez-Villanueva ${ }^{2}$, P. Lomeli ${ }^{3}$, and W.N.P. Hung ${ }^{1} \otimes$

'Texas A\&M University, MS 3367, College Station, Texas 77843, USA

${ }^{2}$ Advanced Material Research COMIMSA, Coahuila, Mexico

${ }^{3}$ Keysight Technologies, Santa Rosa, California, USA

E-mail: hung@tamu.edu

Reference: Feng, Z., Orona-Hinojos, J. M., Perez-Villanueva, P., Lomeli, P., and Hung, W. N. P. (2017). Flushing Enhancement with Vibration and Pulsed Current in Electrochemical Machining. International Journal of Engineering Materials and Manufacture, 2(4), 67-85. 


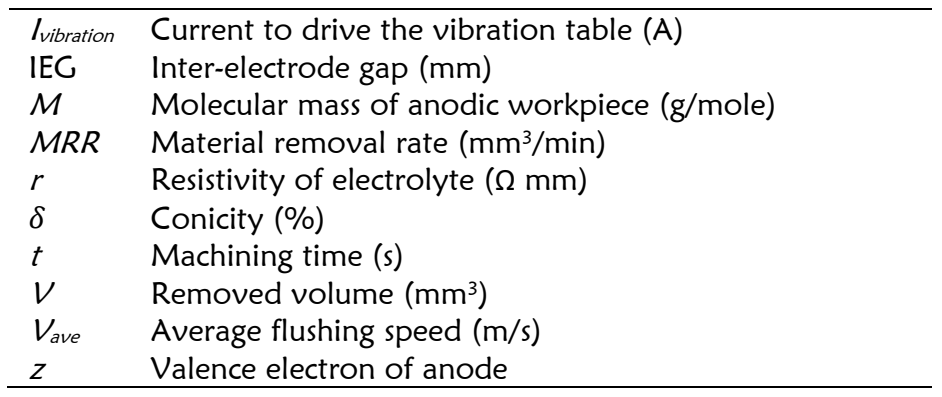

\section{INTRODUCTION}

The emphasis on fuel economy and passenger safety have led to a remarkable increase in the usage of high strength low alloy (HSLA) steels in automobile application due to their high strength-to-weight ratio, and higher fatigue resistance than carbon steel. Engineering components using HSLA steels usually have complex geometries and are manufactured by various metal forming techniques. Fabrication of holes and slots on HSLA steel, for example, is a common work procedure when designing engineering components. Drilling, milling, punching, laser cutting and electro-discharging machining (EDM) are general processes that applied to shape a component. However, microstructural damages, expensive deburring and time consuming residual stress relieving treatment prompt researchers to consider alternative manufacturing techniques.

Cubic boron nitride (CBN) and coated carbide tools are required when machining HSLA steels due to its high strength and poor machinability. High energy is required to shear the chips which results in thermal-induced defects in the materials and costly tool wear. When punching/stamping HSLA steels, it requires high energy, very tough yet hard cutting tool material, high stiffness of tool holder, are pre-requisites for successful punching holes on HSLA steels due to work-hardening property of HSLA steels. Although laser cutting has the advantages of no mechanical cutting forces and tool wear; its high energy-consumption, low MRR, tapering cutting profile, thermally induced residual stress on laser cut surfaces are inherent drawbacks of this process. In the EDM process a conductive material can be removed without mechanical contact forces and independent of material hardness. Although EDM can be used to form features on HSLA steels, but a defective EDM'ed subsurface and relatively slow MRR limit the application of EDM for demanding and high volume applications. A recast layer after EDM'ing is under high residual stress and may contain voids and microcracks; heat affected zone beneath recast layer undergoes microstructure morphing; insufficient flushing leads to abnormal discharging and resulting in extensive electrode wear. In all traditional and nontraditional processes, inevitable burrs are formed and must be removed in subsequent operations that further drives up the lead time and manufacturing cost.

Electrochemical machining has been applied in aerospace, automobile, medical, and, recently, in micro manufacturing. This technique, based on the principle of controlled atomic-level anodic dissolution, has been used to fabricate complex shapes from any electrically conductive components. This is particularly useful to shape engineering alloys that are difficult to be machined such as HSLA steels, tool steels, tungsten carbides and super alloys. Moreover, ECM does not induce any thermal or mechanical stresses/surface effects on the workpiece, the process generates no burr, has no tool wear, yet can achieve excellent surface quality as in electrochemical polishing. Eliminating secondary processes for deburring and stress relieving, the ECM is a promising technique to machine/polish HSLA steels if a decent material removal rate can be achieved.

Ion transport movement is the basic mechanism that controls the material removal rate in ECM. When two electrically conductive materials are closely placed in the presence of an electrolytic fluid that conducts ions, the anodic workpiece releases ions towards the cathodic electrode. If the cathodic electrode (tool) moves at a controlled feed rate and motion toward anode, a desirable shape can be formed on the anodic workpiece. An electrolyte flows between two electrodes to enhance ion transport, maintain the temperature, and flush the resulted debris. If the newly formed by-products in inter-electrode gap (IEG) are not effectively flushed away from an anode surface, cumulative ions would be stagnant and inhibits further ion dissolution, therefore, affecting material removal rate (MRR) and quality of ECM'ed profile. Thus, increase the ion transport rate and effective flushing of by-products are keys to improve the material removal rate. The movement of ions is controlled by three processes [1]:

i) Migration, i.e. movement under the influence of the electric field;

ii) Diffusion, i.e. movement due to ion concentration gradients in the solution;

iii) Convection, i.e. bodily movement of the electrolyte solution; this is mainly effected by force agitation of the electrolyte in ECM.

Therefore, a high MRR requires fast ion and by-product movement rates (i.e. migration rate, diffusion rate and convection rate). Researchers have attempted to utilize different techniques to improve these transport rates: by applying a high voltage to increase migration rate, increasing high electrolyte flow rate to increase diffusion rate, vibrating either workpiece or electrode to increase MRR. A study of by-product flushing in ECM to enhance the MRR with pulsed current and low frequency workpiece vibration is the focus of this research. 


\section{LITERATURE REVIEW}

\subsection{Electrolysis}

Since the major composition of HSLA steel is iron (97-99\%), during ECM process several possible reactions may occur at the workpiece and electrode. The reaction is the dissolution of iron at anode.

$$
F e \rightarrow F e^{2+}+2 e^{-}
$$

At the electrode, hydrogen and hydroxyl ions are produced:

$$
2 \mathrm{H}_{2} \mathrm{O}+2 e^{-} \rightarrow \mathrm{H}_{2} \uparrow+2 \mathrm{OH}^{-}
$$

Thus, the overall reaction of iron in ECM process is:

$$
\mathrm{Fe}+2 \mathrm{H}_{2} \mathrm{O} \rightarrow \mathrm{Fe}(\mathrm{OH})_{2}+\mathrm{H}_{2} \uparrow
$$

Ferrous hydroxide $\mathrm{Fe}(\mathrm{OH})_{2}$ may further react with water and oxygen to form ferric hydroxide $\mathrm{Fe}(\mathrm{OH})_{3}$.

$$
\mathrm{Fe}(\mathrm{OH})_{2}+2 \mathrm{H}_{2} \mathrm{O}+\mathrm{O}_{2} \rightarrow 4 \mathrm{Fe}(\mathrm{OH})_{3}
$$

The iron dissolution rate (material removal rate) is governed by Faraday's two laws of electrolysis:

i) The amount of any substance dissolved or deposited is directly proportional to the amount of electrical charges which has flowed;

ii) The amounts of different substances deposited or dissolved by the same quantity of electrical charges are proportional to their chemical equivalent weights.

The two laws may be combined to give the equation:

$$
M R R=\frac{V}{t}=\left(\frac{M}{z F d}\right) \frac{E A}{g r}=C \frac{E A}{g r}
$$

Where; $M R R=$ material removal rate $\left(\mathrm{mm}^{3} / \mathrm{s}\right), V=$ removed volume $\left(\mathrm{mm}^{3}\right), M=$ molecular mass of anodic workpiece (g/mole), $d=$ workpiece density $\left(\mathrm{g} / \mathrm{cm}^{3}\right), E=$ applied voltage $(\mathrm{V}), A=$ effective electrode area $\left(\mathrm{mm}^{2}\right), g$ $=$ inter-electrode gap $(\mathrm{mm}), r=$ resistivity of electrolyte $(\Omega \mathrm{mm}), z=$ valence electron of anode, $t=$ machining time $(\mathrm{s}), F=$ Faraday constant $=96500$ Coulomb/mole, and $C$ : specific removal rate of workpiece $\left(\mathrm{mm}^{3} / \mathrm{A} / \mathrm{s}\right)$.

Although equation (5) suggests the MRR is the volume removal rate, some researchers change it to mass removal rate for the convenience of measurement.

\subsection{Effect of Higher Voltage}

The original Faraday's work used direct current for electrolytic plating; it assumed the anodic ion removal rate is the same as the rate for ion depositing on cathode and chemical replenishing rate. From equation (5), a higher applied voltage would result in a higher $M R R$.

ECM using copper electrode with square cross section, $\phi 20 \times 40 \mathrm{~mm}$ high carbon alloy steel workpiece, $10 \%$ $\mathrm{NaCl}$ electrolyte with $6 \mathrm{~m} / \mathrm{s}$ flow rate and $0.2 \mathrm{~mm}$ IEG was investigated [3]. When the applied voltage increased from $24 \mathrm{~V}$ to $32 \mathrm{~V}$, the resulted $M R R$ increased $15 \%$ from $2.575 \mathrm{mg} / \mathrm{min}$ to $2.960 \mathrm{mg} / \mathrm{min}$. Similarly, other researchers [4] used copper electrode with square cross section, $\phi 30 \times 6 \mathrm{~mm}$ alloy steel workpiece, $20 \mathrm{~g} / \mathrm{L} \mathrm{NaNO}_{3}$ electrolyte with $7 \mathrm{~L} / \mathrm{min}$ electrolyte flow rate and $0.6 \mathrm{~mm} / \mathrm{min}$ electrode feed rate. When the applied voltage increased from 12 $V$ to $16 \mathrm{~V}$, the authors found that MRR increased $23 \%$ from $0.0514 \mathrm{~g} / \mathrm{min}$ to $0.0634 \mathrm{~g} / \mathrm{min}$. The trend was also reconfirmed by other authors [5] who used $\phi 16 \mathrm{~mm}$ solid brass electrode, $\phi 19 \mathrm{~mm}$ EN-8 steel workpiece, $45 \mathrm{~g} / \mathrm{L}$ $\mathrm{NaCl}$ with $12 \mathrm{~L} / \mathrm{min}$ electrolyte flow rate and $0.8 \mathrm{~mm}$ IEG. When the applied voltage increased from $10 \mathrm{~V}$ to $30 \mathrm{~V}$, the MRR increased a significant $204 \%$ from $0.33445 \mathrm{~g} / \mathrm{min}$ to $1.01855 \mathrm{~g} / \mathrm{min}$.

It has been experimentally verified that $M R R$ increases with applied voltage or current. On an active material that forms a passive film on its surface, a higher current would breakdown the passivated film and facilitate the electrochemical reaction between electrodes [6]. In addition, a higher voltage facilitates the migrating rate which also enhances $M R R$ due to accelerating ion transport.

\subsection{Effect of Pulsed Current}

In a conventional electrochemical machining, a DC power is generally applied, and the electrolyte between interelectrode gap is easily boiled due to the energy dissipation of high current density, which results in a varying local distribution of electrolyte conductivity and hence leads to poor machining accuracy. A higher voltage/current also results in more undesired products and heat which require a higher electrolyte flow rate to remove. Pulsed current, 
instead of direct current, has been applied in ECM to enhance the process. Pulsed ECM leads to higher dimension accuracy, better surface quality, better process stability, and suitability to online process control. These benefits are obtainable due to several factors [7]:

i) Enhancing localized anodic dissolution,

ii) Improving electrolyte hydrodynamic uniformity in the IEG by removing undesired by-products and reducing heat during off-time,

iii) Reducing and stabilizing IEC, and

iv) Reducing required electrolyte flow rate.

When applying pulsed voltage in ECM, the combination of peaked voltage, duty cycle and voltage frequency exert influence on MRR and dimension accuracy.

ECM using $\phi 9.5 \mathrm{~mm}$ stainless steel electrodes with Teflon coated on both outside and inside, $60 \mathrm{~mm} \times 40 \mathrm{~mm}$ $\times 6.3 \mathrm{~mm} 1018$ steel workpiece, $1 \mathrm{~mol} / \mathrm{L} \mathrm{KBr}$ electrolyte, $13 \mathrm{~A}$ average current was studied [8]. When the current frequency was switched from 0 to $60 \mathrm{~Hz}$, the MRR increased slightly from 34.3 to $34.9 \mathrm{~mm} / \mathrm{min}$, but when increasing the current frequency to $100 \mathrm{~Hz}$, the MRR then increased to $36.4 \mathrm{~mm}^{3} / \mathrm{min}$.

Other authors used $\phi 200 \mu \mathrm{m}$ platinum wire electrode, $6 \mathrm{~mm} \times 4 \mathrm{~mm} \times 0.4 \mathrm{~mm}$ copper plate workpiece, $15 \mathrm{~g} / \mathrm{L}$ $\mathrm{NaNO}_{3}$ electrolyte, $10 \mathrm{~V}$ peak voltage and $50 \mathrm{~Hz}$ voltage frequency. When the duty cycle increased from $25 \%$ to $75 \%$, the MRR increased $500 \%$ from $0.2 \mathrm{mg} / \mathrm{min}$ to $1.2 \mathrm{mg} / \mathrm{min}$ but the overcut also increased from $0.04 \mathrm{~mm}$ to $0.07 \mathrm{~mm}[9]$.

Some researchers [10] used $\phi 335 \mu \mathrm{m}$ stainless wire electrode, $15 \mathrm{~mm} \times 10 \mathrm{~mm} \times 0.15 \mathrm{~mm}$ bare copper workpiece, $20 \mathrm{~g} / \mathrm{L} \mathrm{NaNO}_{3}$ electrolyte and $3.5 \mathrm{~V}$ peak voltage. For a specific value voltage frequency, i.e. at $35 \mathrm{~Hz}, \mathrm{MRR}$ initially increased with an increase of duty cycle to the maximum value, but the MRR then decreased with further increasing in duty cycle at a preset machining parameters. The paper cited that the MRR increased with an increase of duty cycle due to more machining time. With further increased in duty cycle, the MRR decreased in small span of off time due to inefficient removing of by-products from the machining zone that led to improper dissolution of workpiece material. In addition, radial over cut increased with increasing duty cycle. Since by-products were inefficiently flushed away from machining zone during shorter off-time (i.e. higher duty cycle), the presence of by-product microparticles between electrodes would increase the chance of micro-sparking when high voltage applied and hence increased the radial over cut. Moreover, localized effect diminished with an increasing in duty cycle. For a specific duty cycle, i.e. $60 \%$, when voltage frequency increased from 35 to $55 \mathrm{~Hz}$, the $M R R$ increased $12 \%$ from 0.821948 to $0.91998 \mathrm{~g} / \mathrm{min}$ and the radial overcut increased from 0.161 to $0.203 \mathrm{~mm}$.

\subsection{Effect of Electrolyte Flow Rate}

Diffusion rate is another major factor that affects the ion transport. Although an electrolyte can be static in theory, it is commonly pumped at high flow rate to flush away by-products, reduce electrolyte temperature and replenish fresh electrolyte in IEG.

ECM with copper electrode with square cross section, $\phi 30 \times 6 \mathrm{~mm}$ alloy steel workpiece, $20 \mathrm{~g} / \mathrm{L} \mathrm{NaNO}$ electrolyte, $0.6 \mathrm{~mm} / \mathrm{min}$ electrode feed rate and $14 \mathrm{~V}$ applied voltage was investigated [11]. When the flow rate increased from $5 \mathrm{~L} / \mathrm{min}$ to $9 \mathrm{~L} / \mathrm{min}$, the $M R R$ increased $98 \%$ from 0.0242 to $0.0478 \mathrm{~g} / \mathrm{min}$, and the surface roughness reduced from 3.241 to $2.785 \mu \mathrm{m}$.

Other authors [5] used $\phi 16 \mathrm{~mm}$ solid brass electrode, $\phi 19 \mathrm{~mm}$ EN-8 steel workpiece, $45 \mathrm{~g} / \mathrm{L} \mathrm{NaCl}$ electrolyte, 20 $V$ applied voltage and $0.8 \mathrm{~mm}$ IEC. When the electrolyte flow rate increased from 10 to $14 \mathrm{~L} / \mathrm{min}, M R R$ increased $52 \%$ from 0.5526 to $0.84095 \mathrm{~g} / \mathrm{min}$ and overcut is reduced from 0.275 to $0.25 \mathrm{~mm}$.

However, a high electrolyte flow rate requires an elaborate pumping system and a heavy machine frame to maintain rigidity. A very high flow rate may introduce two drawbacks: i) non-uniform electrolyte hydrodynamic condition in the IEG result in poor machining dimensional accuracy and ii) cavitation results in poor surface quality.

\subsection{Effect of Ultrasonic Vibration}

In addition to low frequency vibration of workpiece or electrode, some researchers explored the effect of ultrasonic vibration on ECM process. Some authors [12] used brass electrode, NC6 steel workpiece, 20-120 W ultrasonic vibration power with $10 \mu \mathrm{m}$ maximum vibration amplitude at $20 \mathrm{kHz}$. They found a slight improvement in surface finish $R_{a}$ from $1.5 \mu \mathrm{m}$ to $1.0 \mu \mathrm{m}$, and concluded that specific ultrasonic amplitude for each combination of machining parameters would result in an optimal surface finish. Instead of applied ultrasonic vibration on electrode or workpiece, some researchers set up an ECM cell in ultrasonic baths at either $20 \mathrm{kHz}$ or $56 \mathrm{kHz}$ [13]. The effect of ultrasonic wave was expected by the transmission of high frequency wave through the glass walls of the electrochemical cell. Using $10 \mathrm{~A}$ current and changing vibration frequencies from 0 to $20 \mathrm{kHz}$, the authors found the $M R R$ increased slightly from $0.194 \mathrm{~g} / \mathrm{min}$ to $0.197 \mathrm{~g} / \mathrm{min}$. When increasing vibration frequency to $50 \mathrm{kHz}$, the $M R R$ increased to $0.207 \mathrm{~g} / \mathrm{min}$. The study concluded that insignificant improvement was due to the ineffective transmission of ultrasonic wave through glass wall into the IEG gap of ECM cell.

Other researchers [14] used ultrasonic probe to send $20 \mathrm{kHz}$ ultrasonic wave to workpiece surface via flowing electrolyte. The authors used 6061-T6 aluminum workpieces of $60 \mathrm{~mm} \times 50 \mathrm{~mm} \times 6.3 \mathrm{~mm}$, Teflon coated stainless steel tubular electrode with $\phi 9.5 \mathrm{~mm}$ outer diameter and $\phi 8.9 \mathrm{~mm}$ inner diameter, $1 \mathrm{~mol} / \mathrm{L} \mathrm{KBr}$ electrolyte, $22 \mathrm{~A}$ 
peak current. When applying $275 \mathrm{~Hz}$ current frequency and increasing ultrasonic amplitudes from 0 to $15 \mu \mathrm{m}$, the authors found improvement of surface roughness $R_{a}$ from 2.5 to $1.1 \mu \mathrm{m}$ but at the expense of MRR. The generation and implosion of microbubbles due to cavitation at workpiece surface interfered with ionization mechanism at anode, they concluded.

\subsection{Effect of Low Frequency Mechanical Vibration}

Convection is the most significant factor that affects ion transport mechanism. To improve the convection rate, researchers have attempted to vibrate either electrode or workpiece at different vibration frequency and amplitude to enhance the process. Low-frequency vibration of either anode (workpiece) or cathode (electrode) cyclically alters the IEC to enhance flushing of debris while refreshing the anode surface with new electrolyte.

Assuming perfect synchronization of pulsed current and workpiece vibration, a single vibration cycle can be divided into two individual movements: a downward movement (that reduces IEG) and an upward movement (that increases IEG). A smaller IEG reduces the system resistance, increases the current passing through the electrode, and removes more material from the anode by ionization. On the other hand, a large IEC enhances flushing conditions of by-products and helps to bring in fresh electrolyte for the next cycle.

Some researchers [15] pointed out that longitudinal vibration in ECM enhanced the circulation of electrolyte. At the maximum IEG, the decreased pressure in IEC generates transient cavitation or micro bubbles of electrolyte vapor. During the next half vibration cycle, the tool moved toward to workpiece. While in the minimum IEC, pressure inside the IEG increased and micro bubbles collapses rapidly. This phenomenon generated electrolyte turbulence which drives out reaction products from the machining zone. Fresh electrolyte was forced in IEG when tool moves away from the workpiece in the next oscillate cycle.

Other investigators [16] used brass tube electrode with $\phi 8 \mathrm{~mm}$ outer diameter and $\phi 3.5 \mathrm{~mm}$ inner diameter, 20 $\mathrm{g} / \mathrm{L} \mathrm{NaCl}$ electrolyte, $6 \mathrm{~L} / \mathrm{min}$ electrolyte flow rate, $1 \mathrm{~mm} / \mathrm{min}$ electrode feed rate, $18 \mathrm{~V}$ applied voltage and $50 \mathrm{~Hz}$ voltage frequency. The electrode was externally insulated with a thin layer using epoxy resin to avoid undesired side cutting. Experimental results illustrated that significant effect of the tool vibration amplitude on the overcut value was pronounced at the lowest tool amplitude values ( $20 \mu \mathrm{m}$ peak-to-peak). The value of the overcut decreased with a ratio of $15 \%$ at tool amplitude of $20 \mu \mathrm{m}$ (peak-to-peak) more than that with zero tool amplitude. The result was due to the fact that a higher tool amplitude value caused a greater stray current during the tool motion, which led to an increase of $M R R$ on the side of workpiece. Conicity is defined as:

$$
\delta=\frac{D_{1}-D_{2}}{2 H} \times 100
$$

Where; $\delta=$ conicity (\%), $D_{1}=$ hole diameter at level $1(\mathrm{~mm}), D_{2}=$ hole diameter at level $2(\mathrm{~mm})$, and $H=$ height between the two level (mm).

The conicity decreased with increasing vibration amplitude. The application of low-frequency vibration to the ECM tool reduced workpiece conicity with a ratio about $23 \%(4.5 \%-3.5 \%)$ than that without vibration. This effect was due to the effectiveness of the pumping action at the frontal zone, intense flushing of the IEC with fresh electrolyte and evacuation of the by-products, which resulted in the decrease of lateral material removal and conicity improvement.

Other authors [10] used $\phi 335 \mu \mathrm{m}$ stainless steel wire electrode, $10 \mathrm{~mm} \times 10 \mathrm{~mm} \times 0.15 \mathrm{~mm}$ bare copper workpiece, $20 \mathrm{~g} / \mathrm{L} \mathrm{NaNO}$ electrolyte, $3.5 \mathrm{~V}$ applied voltage, $45 \mathrm{~Hz}$ voltage frequency and $60 \%$ voltage duty cycle. When the vibration frequency increased from $100 \mathrm{~Hz}$ to $300 \mathrm{~Hz}$, the resulted $M R R$ increased 10\% from $0.89469 \mathrm{~g} / \mathrm{min}$ to $0.98655 \mathrm{~g} / \mathrm{min}$. The authors concluded that at higher vibration frequency, the $M R R$ increased from the consequence of proper dissolution of anode material and greater amount of reaction material being flushed away from IEC.

Others [2] used $\phi 160 \mu \mathrm{m}$ tungsten electrode with $5 \mu \mathrm{m}$ insulate layer, 321 stainless steel workpiece with $0.5 \mathrm{~mm}$ thickness, $5 \mathrm{wt} \% \mathrm{NaNO}_{3}+0.8 \mathrm{wt} \%$ EDTA-Na2 electrolyte, $6 \mathrm{~V}$ voltage with $50 \%$ duty cycle, $2 \mathrm{KHz}$ pulsed voltage and $15.6 \mu \mathrm{m}$ IEG, 3-14 $\mu \mathrm{m}$ vibration amplitude, and 50-200 Hz vibration frequency. These authors applied low frequency vibration on the workpiece instead of electrode, pointed out that a low frequency vibration would help the overall process efficiency by:

i) Ejecting reaction products away from the electrode faces, and

ii) Maintaining a stable electrolyte field within IEC, therefore enhancing MRR.

At a low vibration frequency of $50 \mathrm{~Hz}$, the MRR increased about 5 times to $0.0388 \mathrm{mg} / \mathrm{min}$ (when vibration at $12 \mu \mathrm{m}$ amplitude) from $0.0062 \mathrm{mg} / \mathrm{min}$ (without vibration). A peak value of $M R R$ existed at certain amplitude for each vibration frequency, i.e., at $50 \mathrm{~Hz}, 12 \mu \mathrm{m}$ vibration amplitude generated maximum $M R R$. On the contrary, at higher vibration frequency of $200 \mathrm{~Hz}$, the vibration amplitude had negligible influence on $M R R: 0.0066 \mathrm{mg} / \mathrm{min}$ at $8 \mu \mathrm{m}$ vibration amplitude, compared with $0.0062 \mathrm{mg} / \mathrm{min}$ without vibration. At constant vibration amplitude, the MRR initially increased then decreased with increasing vibration frequency. For a preset vibration amplitude $(4,6$, and $8 \mu \mathrm{m}$ ), the resulted $M R R$ initially increased as vibration increased, but after obtaining the maximum MRR at 50 $\mathrm{Hz}$, then $M R R$ decreased with increasing of vibration frequency. 
Effect of large range vibration frequency was also studied [17]. The authors used stainless steel electrode, $15 \mathrm{~mm}$ $\times 10 \mathrm{~mm} \times 0.15 \mathrm{~mm}$ bare copper plate workpiece, $20 \mathrm{~g} / \mathrm{L}$ sodium nitrate electrolyte, $3 \mathrm{~V}$ voltage, $55 \mathrm{~Hz}$ voltage frequency, $66 \%$ duty cycle and $0.144 \mathrm{~mm} / \mathrm{min}$ electrode feed rate. A wide range of frequency $50-23,000 \mathrm{~Hz}$ was selected for electrode vibration. Vibration amplitude was 4.5 V-RMS. Experimental results showed that electrode vibration at $\mathrm{kHz}$ ranges had no significant influence on $M R R(\sim 0.6 \mathrm{mg} / \mathrm{min})$ and overcut $(\sim 0.1 \mathrm{~mm})$. However, at lower ranges of electrode vibration, a higher $M R R(\sim 1.75 \mathrm{mg} / \mathrm{min})$ and lower overcut $(0.04 \mathrm{~mm})$ were obtained. The enhanced MRR and dimension accuracy attributed to the introduction of electrode tool vibration in $\mathrm{Hz}$ range during ECM process which eliminated the passive layer from the effective machining area of workpiece surface, and thereby improved the ECM actions.

To continue improve $M R R$ in vibration-assisted $E C M$, synchronization of mechanical vibration with pulsed current was introduced. During this process, the electrode feeding toward the anode was overlaid with cathode vibration, which results in two different process phases. During minimize gaps size, a pulse current with a pulse duration applied. The resistance between IEG will decreased due to the tool vibration, which led to more efficient material dissolution. The maximum gap size achieved when electrode moved away from workpiece, which improved the flushing conditions and hence a better removal of the reaction products as compared to the minimum gap size condition [18].

Experimental data from literature show that ultrasonic vibration would improve ECM'ed surface finish and low frequency vibration would improve MRR. This research fills the gap by studying vibration-enhanced ECM at low frequencies than $50 \mathrm{~Hz}$ from both theoretical and experimental approaches. The following sections detail the experimental procedure and steps to simulate the flushing of by-products, and then compare simulation results with experimental data on $M R R$ and quality of ECM'ed features.

\section{EXPERIMENTS}

A horizontal vibration assisted ECM system was developed in this study. Referring to Figure 1, a workpiece plate (\#5) was mounted with workpiece surface in vertical direction and an electrode (\#6) traveled horizontally into the workpiece with feed rate controlled by a computer controlled positioner (\#7). Workpiece vibration was precisely generated by an electrodynamic shaker (\#1). A pulsed power supply (\#13) and two high-flow-rate pumps (\#11, 16) completed the ECM cell. Details of the cell components are listed in Table 1.

Stainless steel tubes ( $\phi 9.5 \mathrm{~mm}$ OD, $0.3 \mathrm{~mm}$ thick) were selected as electrodes. Both $13 \mathrm{~mm}$ ends of an electrode were commercially coated with Teflon to form a nonconductive layer of $0.02 \mathrm{~mm}$ thick on both outside and inside. The coated ends were carefully sanded off using 600-grit abrasive paper to make it electrically conductive.

Although the main application of this study was for ECM of Domex 550MC HSLA steel, plain carbon 1018 steel was used in the experiments. By calculating specific material removal rates (the variable $C$ in equation (5)) of each chemical elements of each materials (Table 2), it can be shown that the specific material removal rates of both materials are comparable: $C_{1018 \text { steel }}=3.67 \times 10^{-2} \mathrm{~mm}^{3} /$ As and $C_{\text {Domex }}=3.63 \times 10^{-2} \mathrm{~mm}^{3} /$ As [8]. Workpieces were sawed and ground to rectangular samples $(50 \times 60 \times 3.5 \mathrm{~mm})$. Relevant physical and mechanical properties of two materials are shown in Table 3.

Table 1: ECM set-up components

\begin{tabular}{llll}
\hline 1 & Labworks ET-132 electrodynamic shaker & 11 & Longer WT600-2J peristaltic pump \\
2 & Bearing housing & 12 & Positive electric wire (to workpiece) \\
3 & Linear bearing & 13 & Everlast 255EXT power supply \\
4 & Stainless steel shaft & 14 & Negative electric wire (to electrode) \\
5 & Workpiece & 15 & Fresh-electrolyte tube \\
6 & Electrode & 16 & Longer WT600-2J peristaltic pump \\
7 & 3-axis Velmex positioner & 17 & Fresh-electrolyte container \\
8 & Granite table & 18 & Shaft coupling \\
9 & Used-electrolyte container & 19 & ECM cell with flash guard housing \\
10 & Used-electrolyte tube & 20 & Electrode holder \\
\hline
\end{tabular}

Table 2: Chemical composition of steels

\begin{tabular}{ll}
\hline Materials & Mass \% \\
\hline 1018 steel & $98.8-99.3 \mathrm{Fe}, 0.14-0.2 \mathrm{C}, 0.6-0.9 \mathrm{Mn}$ \\
Domex 550MC & $97.5 \mathrm{Fe}, 1.80 \mathrm{Mn}, 0.12 \mathrm{C}, 0.1 \mathrm{Si}, 0.15 \mathrm{Ti}, 0.2 \mathrm{~V}$ \\
\hline
\end{tabular}

The EVERLAST 255 EXT DC power supply provides either DC or pulsed DC of 3-150 A up to $500 \mathrm{~Hz}$ pulsed current frequency. Since a high peak current may generate sparks that damage the workpiece and electrode, the peak current was set at $26 \mathrm{~A}$, current frequency at $500 \mathrm{~Hz}$ and $50 \%$ duty cycle for all experiments.

Potassium bromide $(\mathrm{KBr}, 1 \mathrm{~mol} / \mathrm{L})$ was used as electrolyte. Each experiment run was started with electrolyte temperature in the range of $21-25^{\circ} \mathrm{C}$. Temperature or the electrolyte was measured before each experiment using an OMEGA HH374 data logger thermometer. Electrolyte conductivity, measured before each run using the Hannah $\mathrm{HI}$ 8733 conductivity meter, was in the range of $111-121 \mathrm{mS} / \mathrm{cm}$. Although the metallic by-products in used electrolyte could be filtered using centrifugal method in small quantity, the settling method was used for a large quantity of used 
electrolyte. In the later method, the used electrolyte mixed with metallic by-products was stored in a used electrolyte container overnight so that the heavy metallic and salt by-products would be settled at the container bottom. The clear electrolyte at the top was separated by a peristaltic pump and used for subsequent experiment if its conductivity was still comparable with that of the fresh electrolyte.
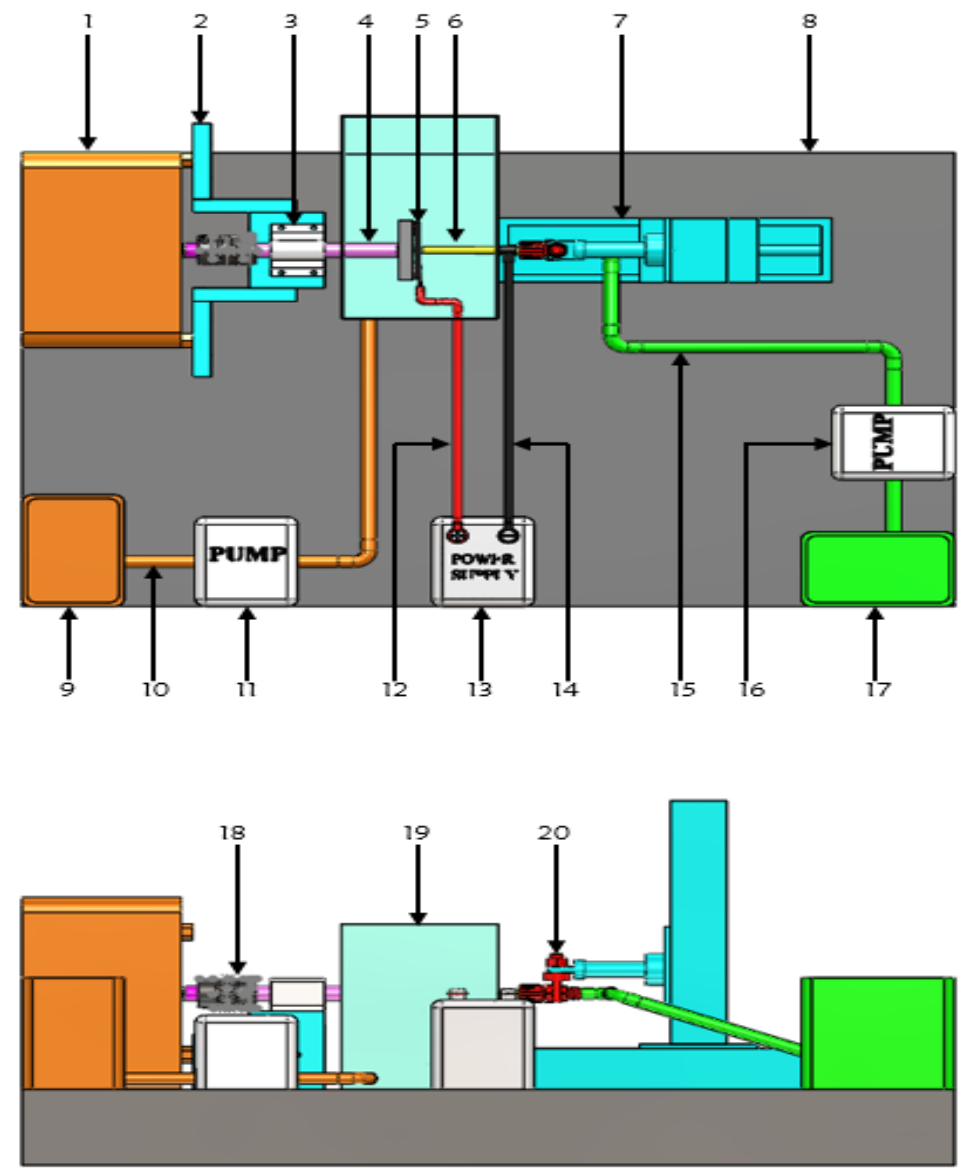

Figure 1: Front and top views of the laboratory ECM system

Table 3: Physical and mechanical properties of 1018 steel *Estimated values from similar alloys [20] ** Estimated values from similar alloys [21]

\begin{tabular}{lll}
\hline Properties & 1018 steel & Domex 550MC \\
\hline Density $\left(\mathrm{g} / \mathrm{cm}^{3}\right)$ & 7.87 & 8.13 \\
Hardness $($ Brinell) & 126 & 550 \\
Melting temperature $\left({ }^{\circ} \mathrm{C}\right)$ & $1450-1510$ & 1520 \\
Shear strength $(\mathrm{MPa})$ & 330 & 371 \\
Tensile strength $(\mathrm{MPa})$ & 440 & 660 \\
Specific heat $\left(\mathrm{J} / \mathrm{g} /{ }^{\circ} \mathrm{C}\right)$ & 0.486 & 0.434 \\
*Thermal conductivity $\left(\mathrm{W} / \mathrm{m}^{\circ} \mathrm{K}\right)$ & 53.6 & 41 \\
*Thermal diffusivity $\left(\mathrm{mm}^{2} / \mathrm{s}\right)$ & 14.7 & 1.6 \\
** Electrical resistivity $(\Omega \mathrm{m})$ & $15.9 \times 10^{-8}$ & $17 \times 10^{-8}$ \\
\hline
\end{tabular}

The Labworks ET-132-2 electrodynamic shaker was powered by the Labworks PA-151 linear power amplifier that in turn controlled by an Agilent 33250A waveform generator. The computer controlled positioner included two Velmex motorized frames, a rotary plate and a VXM-3 controller system. The system has a load capacity of $15.9 \mathrm{~kg}$ horizontally and $4.5 \mathrm{~kg}$ vertically with straight-line accuracy of $0.076 \mathrm{~mm}$ over a linear distance of $25 \mathrm{~cm}$, feed rate range $2.5-5000 \mu \mathrm{m} / \mathrm{s}$, and repeatability of $0.0025 \mathrm{~mm}$. A TENMA 72-6202 multimeter was used to detect electrical contact between conductive electrode and workpiece. Initial inter-electrode gap was set at $0.3 \mathrm{~mm}$ for every experiment. Electrode feed rate was fixed at $15 \mu \mathrm{m} / \mathrm{s}$ and the electrode travel distance was programmed to be 2.5 $\mathrm{mm}$ from the starting position. All experimental conditions are summarized in Table 4. 
After ECM'ed, all samples were rinsed and clean with water in an ultrasonic bath for 1 minute and then dried with compressed air. All samples were positioned in a glass beaker in the bath with ECM'ed holes facing downward to facilitate removal of residual particles from the hole. The Alicona Infinite Focus 3D profiler was used to analyze ECM'ed machined depths, surface finish, and wall taper angles.

Table 4: Summary of experimental conditions

\begin{tabular}{ll}
\hline Variables & Values \\
\hline Current frequency $(\mathrm{Hz})$ & 500 \\
Electrode feed rate $(\mu \mathrm{m} / \mathrm{s})$ & 15 \\
Electrode travel distance $(\mathrm{mm})$ & 2.5 \\
Electrolyte concentration $(\mathrm{mol} / \mathrm{L})$ & 1 \\
Electrolyte conductivity $(\mathrm{mS} / \mathrm{cm})$ & $111-121$ \\
Electrolyte flow rate $(\mathrm{L} / \mathrm{min})$ & 2.5 \\
Starting IEC $(\mathrm{mm})$ & 0.3 \\
Peak current $(\mathrm{A})$ & 26 \\
Vibration amplitude $(\mu \mathrm{m})$ & $0,2.50,4.44,5.00,7.50,10.00$ \\
Vibration frequency $(\mathrm{Hz})$ & $0,20,30,40,60,80$ \\
\hline
\end{tabular}

\section{COMPUTER SIMULATIONS}

Recall that ECM on steel would form iron hydroxide by-products that need to be flush away for effective process (equations 3-4). The by-product was assumed to be spherical particles with dimensions to be measured experimentally. The ANSYS Fluent was used to simulate how the particles would move in vibration assisted pulsed ECM. The effects of vibration frequency and vibration amplitude on particle average flushing speed were investigated.

Figure 2 illustrates the free-body diagram of a particle P in the IEG. The particle, between two electrodes and form and angle $\theta$ with the horizontal axis, is subjected to gravity force, buoyance force, and drag force in flowing electrolyte. Due to the axisymmetric electrode, the drag force is in radial direction away from the tube center. When projecting all forces in the radial direction:

$$
F_{r}=F_{d}-\left(G-F_{b}\right) \sin \theta
$$

Where; $F_{d}=$ drag force, $F_{r}=$ total force along radial direction, $G=$ gravity force, and $F_{b}=$ buoyance force

Since the solid particle density is higher than the density of electrolyte, the buoyance force of this particle is always smaller than its gravity force, thus the minimum value of radial direction force equals to $F_{d}-\left(G-F_{b}\right)$ when $\theta=$ $\pi / 2$, and the maximum value of this force equals $F_{d}+\left(G-F_{b}\right)$ when $\theta=3 \pi / 2$. The location at $\theta=\pi / 2$ is the hardest location for reaction particle to flush away, as shown in

Figure 3a (location A). In this study, location A will be taken as simulation cell zone. The thickness of the electrode is $0.3 \mathrm{~mm}$ (Figure 2) and the initial distance between workpiece and electrode is $0.3 \mathrm{~mm}$, thus the simulation zone is a $0.3 \mathrm{~mm} \times 0.3 \mathrm{~mm}$ square box (

Figure $3 b)$

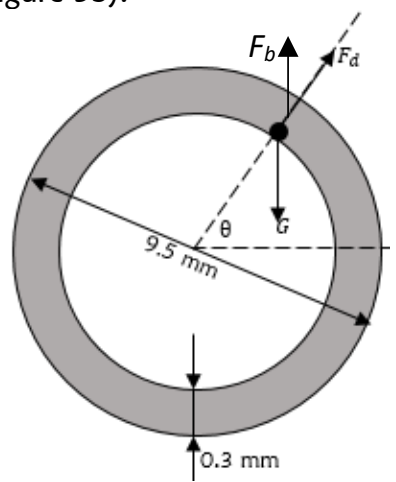

Figure 2: Free-body diagram of particle $\mathrm{P}$ in inter-electrode gap
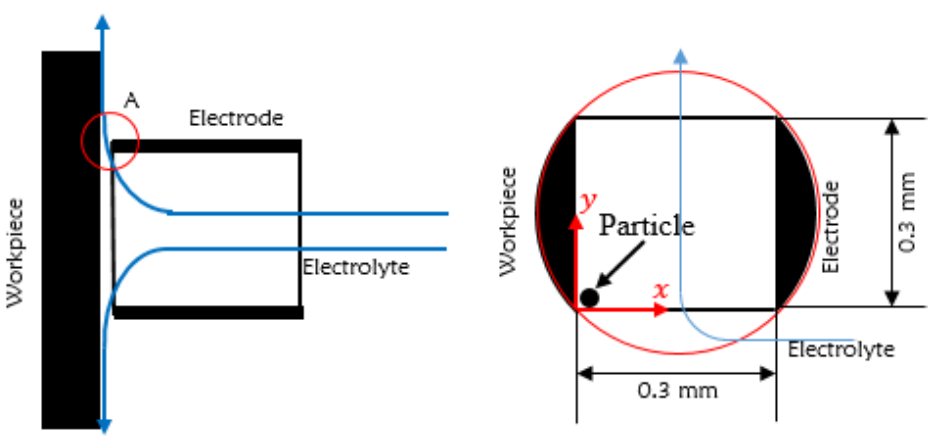

Figure 3 (a) Side view of electrode and workpiece, and (b) enlarged view at the top most position 
Electrolyte flow speeds were set to be 2,3 , and $4 \mathrm{~m} / \mathrm{s}$. The workpiece vibration follows the sine wave:

$$
x=-A \sin (2 \pi f t)
$$

Where; $x=$ location of workpiece relative to the fixed origin (the negative sign means the workpiece movement toward the left and away from the origin), $A=$ vibration amplitude, and $f=$ vibration frequency.

At beginning, the particle center was located at lower left corner (

Figure $3 \mathrm{~b}$ ) with particle initial velocity of $0 \mathrm{~m} / \mathrm{s}$. Boundary conditions in simulation are listed in Table 5 . A simulation procedure stopped when the $y$-coordinate of particle center was larger than $0.3 \mathrm{~mm}$, i.e. when the particle was flushed away from the electrode surface. Simulation steps are detailed in the Appendix.

Table 5: Boundary conditions for first series simulation

\begin{tabular}{ll}
\hline Variables & Values \\
\hline Vibration frequency $f(\mathrm{~Hz})$ & $20,30,40$ \\
Vibration amplitude $A(\mu \mathrm{m})$ & $5.0,7.5,10.0$ \\
\hline
\end{tabular}

Table 6 Corresponding vibration amplitude and frequency at maximum vibration input current (7A)

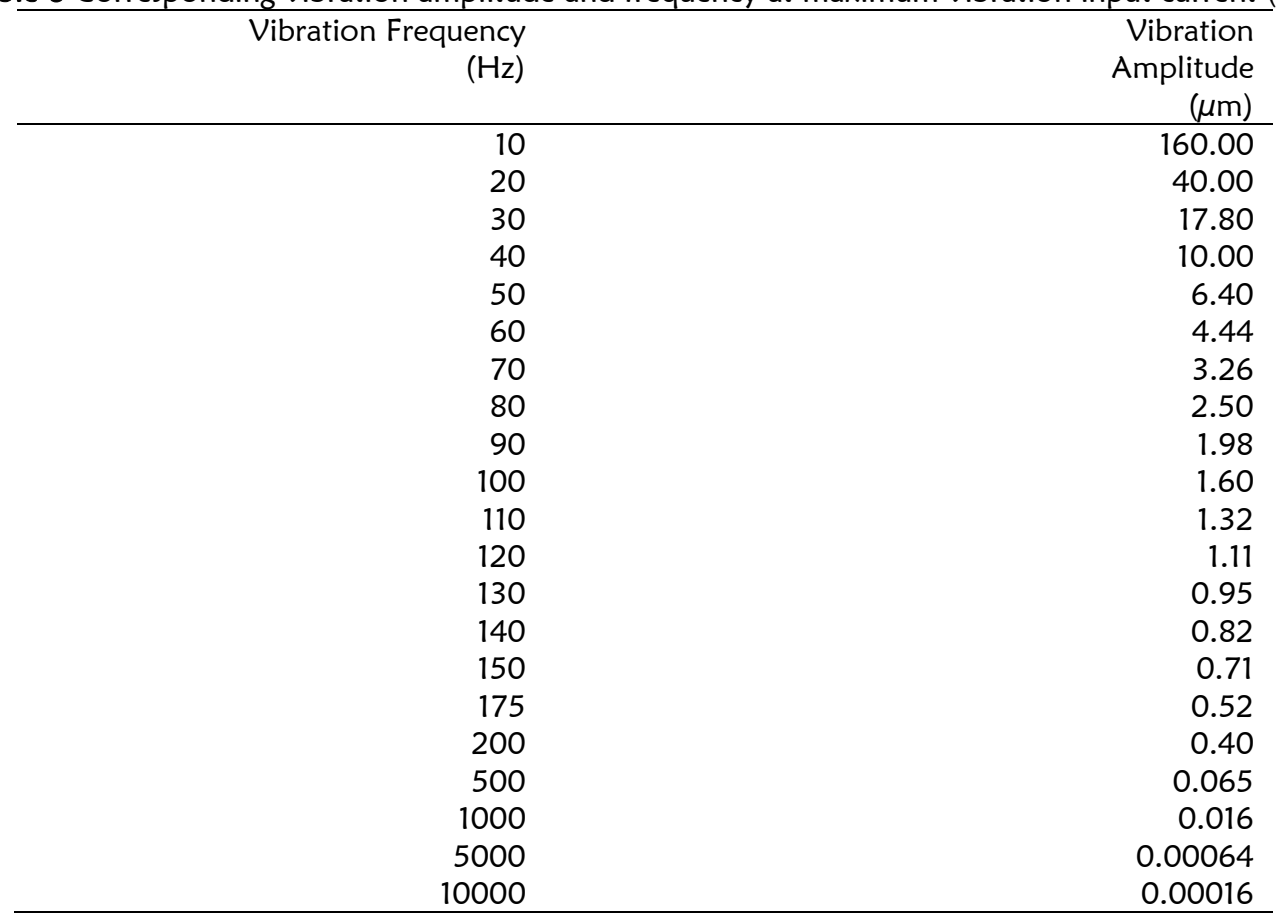

To investigate the influence of the vibration frequency and vibration amplitude and electrolyte flow speed on average flushing speed, two series of simulations were conducted:

i) The first series simulation was used to build a relationship between experimental results and simulation results. Three input levels for each variable were set (Table 5). Thus, total number of simulation run was $3^{2}=9$.

ii) The second series simulation was used to theoretically investigate the maximum flushing speed for the experimental system. The electrolyte flow speed was fixed at $4 \mathrm{~m} / \mathrm{s}$, and input current for vibration table was fixed at its maximum value $(7 \mathrm{~A})$, the corresponding vibration frequency and vibration amplitude will follow $A f^{2}=$ constant based on the specifications of system and are listed in

iii) Table 6.

\section{RESULTS AND DISCUSSIONS}

The effects of vibration amplitude and vibration amplitude on average flushing speed will illustrated by simulation results. Identification of ECM by-product, hole profile, relationship between average flushing speed, and machining depth/taper angle are also demonstrated in the following sections.

\subsection{By-products}


A SEM image of ECM by-products is shown in Figure. Although the particles are coagulated to different shapes, the single particles have different sizes in the range $0.5-4 \mu \mathrm{m}$. It is assumed for simplicity that the particle is spherical with average size of $\sim 2 \mu \mathrm{m}$. An EDX spectrum on dried particles on carbon tape (Figure) suggests that the by-product is iron hydroxide. Elements of the $\mathrm{KBr}$ electrolyte are absent after the by-products were repeatedly rinsed in deionized water.

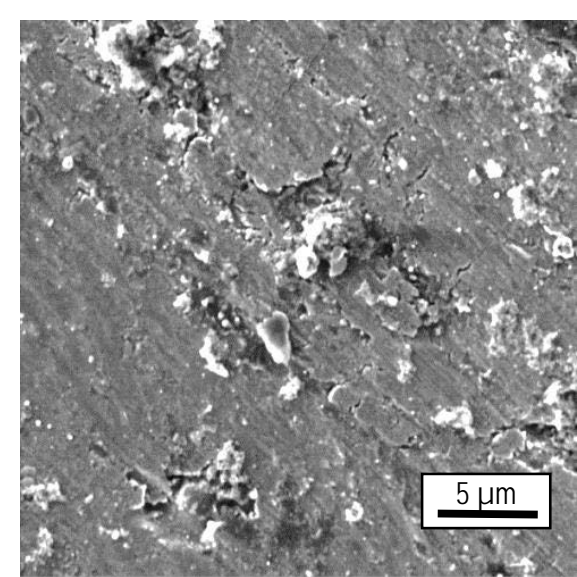

Figure 8: SEM image of dried ECM by products on a titanium plate.

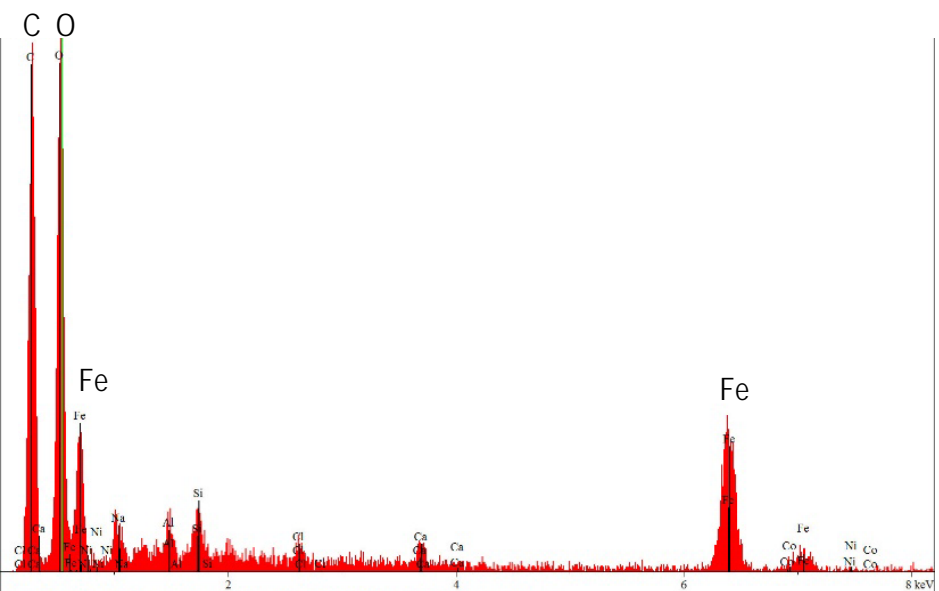

Figure 9: EDX spectrum of ECM by-products on carbon tape. Iron, carbon, and oxygen are dominating elements.

\subsection{Simulation of Average Flushing Speeds}

Recall that the simulation cell is $0.3 \mathrm{~mm} \times 0.3 \mathrm{~mm}$ (

Figure $3 \mathrm{~b}$ ), and a simulation will be terminated if the $y$-coordinate of a particle center is larger than $0.3 \mathrm{~mm}$. A typical particle moves along $y$-direction is shown in Figure 4. Average flushing speed, $V_{\text {ave }}$, is defined as the secant slope of particle path:

$$
V_{\text {ave }}=\frac{\text { particle travel distance }}{\text { time }}
$$

In Figure 4 a particle takes $831 \mu$ s to travel a distance of $300 \mu \mathrm{m}$, then its average flushing speed is $0.3610 \mathrm{~m} / \mathrm{s}$.

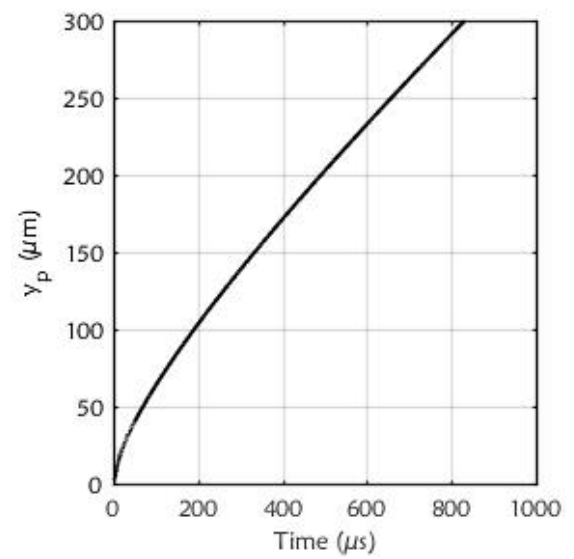

Figure 4: Particle movement in y-direction $(f=20 \mathrm{~Hz}$; $\left.A_{v}=10 \mu \mathrm{m} ; S=4 \mathrm{~m} / \mathrm{s}\right)$

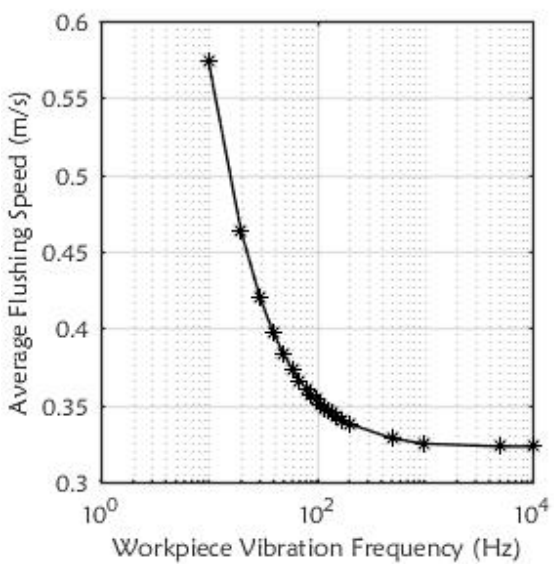

Figure 5: Effect of vibration frequency on average flushing speed at $\mathrm{I}_{\text {vibration }}=7 \mathrm{~A}$

The effect of vibration frequency on average flushing speed at $I_{\text {vibration }}=7 \mathrm{~A}$ is shown in Figure 5 . The average flushing speed decreases with increasing vibration frequency. Neglect the effect of the workpiece vibration on the particle movement along electrode direction, the distance between workpiece and the particle center is:

$$
d_{g}=A_{v} \sin (2 \pi f t)+A_{0}
$$

Where; $d_{g}=$ gap between particle center and workpiece surface $(\mathrm{mm}), A_{\nu}=$ vibration amplitude $(\mathrm{mm}), f=$ vibration frequency $(\mathrm{Hz})$, and $A_{0}=$ initial gap between particle center and workpiece $(\mathrm{mm})$. 
Since $I_{\text {vibration }}=7 \mathrm{~A}$, the average flushing speed decreases from $0.5736 \mathrm{~m} / \mathrm{s}\left(f=10 \mathrm{~Hz}, A_{v}=160 \mu \mathrm{m}\right)$ to 0.3231 $\mathrm{m} / \mathrm{s}\left(f=10,000 \mathrm{~Hz}, A_{v}=0.000,16 \mu \mathrm{m}\right)$ when vibration frequency increases from 10 to $10,000 \mathrm{~Hz}$. For fixed vibration current or constant vibration power, the vibration amplitude and vibration frequency follow the relationship $A_{v} f^{2}=$ $B$ where $B$ is a constant, then equation (10) becomes:

$$
d_{g}=B \frac{\sin (2 \pi f t)}{f^{2}}+A_{0}
$$

Equation (11) suggests that the distance between particle center and workpiece $d_{g}$ decreases drastically with increasing vibration frequency $f$. Therefore, for fixed current on vibration generator a high frequency leads to smaller gap, lesser drag force and lower average flushing speed.

\subsection{Hole Profiles}

The electrical field strength between a circular electrode and a flat plate can be derived [22] and schematically show in Figure 6. The highest field strength is along a circular ring directly below the tubular electrode; the field strength is diminishing outward and away from the tube wall, but is additive to form a pronounced peak at the tubular electrode center. The result is the strong current directly below the electrode, an average current in the central region, and a weaker stray current at positions away from the electrode. The presence of an insulating coating on the electrode side significantly reduces the stray current to improve the ECM efficiency.

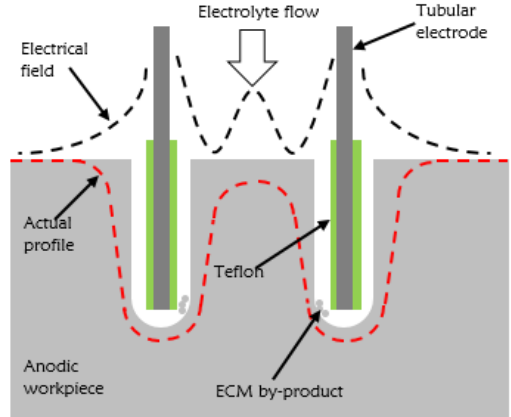

(a)

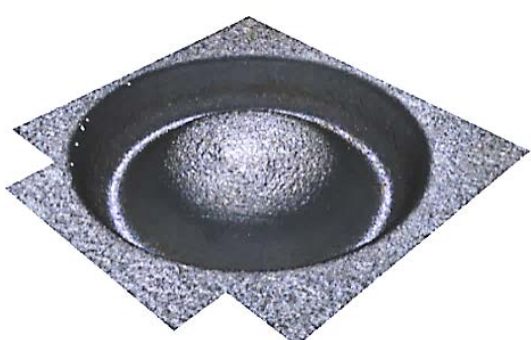

(b)

Figure 6: (a) Electrical field around a tubular electrode, and (b) resulted profile of an ECM'ed hole

The resulted hole profile now can be explained. Significant material is removed directly below the electrode while the corner and center position of a hole are rounded off due to weaker stray current. The agglomerated by-product particles, which collected in a small gap between electrode and workpiece, interfere with the ion transport mechanism if they are not effectively flushed away. However, the flushed particles in fast flowing electrolyte would erode and enlarge the overcut of the ECM'ed profile, and round off the sharp entrance corners.

Figure 7a shows a typical 3D profile measurement of an ECM'ed profile using the Alicona system, from which a cross sectional view can be constructed and analyzed (Figure $7 \mathrm{~b}$ ). Eight locations, $45^{\circ}$ apart, were measured for quality assessment and repeatability. The vertical distance $h$ between top and bottom surface (a-d) is the machining depth. Neglecting the transitional curves $a b$ and $c d$, the slope of line bc can be constructed which defines the corresponding hole taper angle $a$.

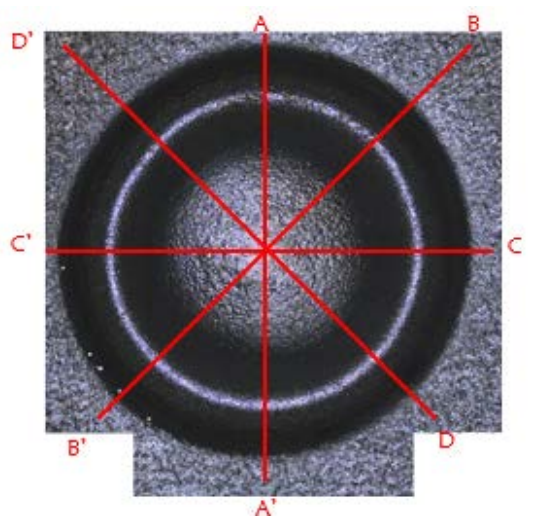

(a)

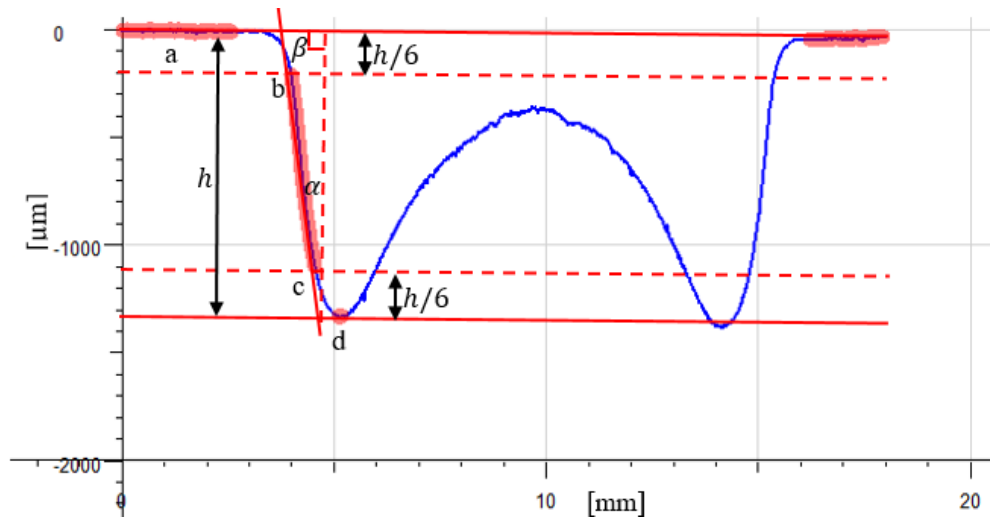

(b)

Figure 7: Typical 3D profile of an ECM'ed hole. $f=20 \mathrm{~Hz}, A_{v}=10 \mu \mathrm{m}, S=4 \mathrm{~m} / \mathrm{s}$ 


\subsubsection{Machining Depths}

The effects of vibration amplitude on average flushing speed and machining depth are demonstrated in Figure 8. At every vibration frequency $(20,30$, and $40 \mathrm{~Hz})$, a higher vibration amplitude causes faster average flushing speed and deeper machining depth. When vibration amplitude increases from $5 \mu \mathrm{m}$ to $10 \mu \mathrm{m}$, the average flushing speeds increase by $5.5 \%(0.3423-0.3610 \mathrm{~m} / \mathrm{s}), 7.8 \%(0.3517-0.3790 \mathrm{~m} / \mathrm{s})$ and $10.0 \%(0.3608-0.3968 \mathrm{~m} / \mathrm{s})$ at respective frequency. Consequently, machining depths increase by $4 \%(1282-1336 \mu \mathrm{m}), 3.7 \%(1311-1360 \mu \mathrm{m})$ and $20 \%(1319$ $1584 \mu \mathrm{m}$ ) at corresponding frequency.

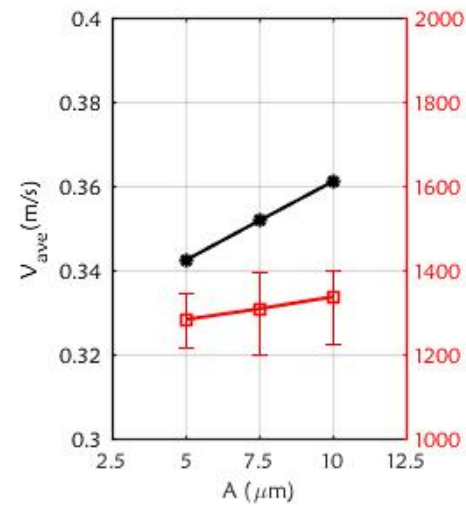

(a) $f=20 \mathrm{~Hz}$

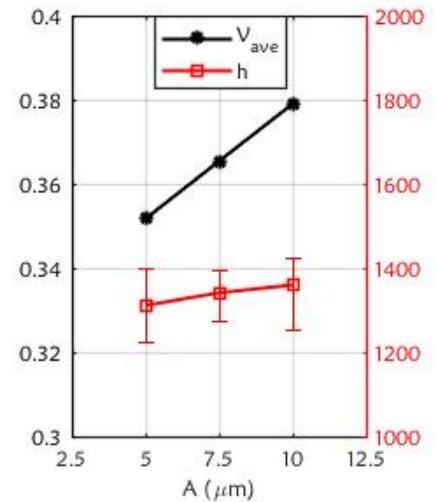

(b) $f=30 \mathrm{~Hz}$

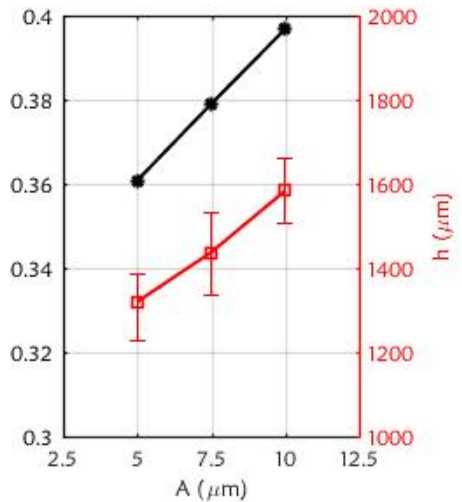

(c) $f=40 \mathrm{~Hz}$

Figure 8: Effect of vibration amplitude on average flushing speed and machining depth

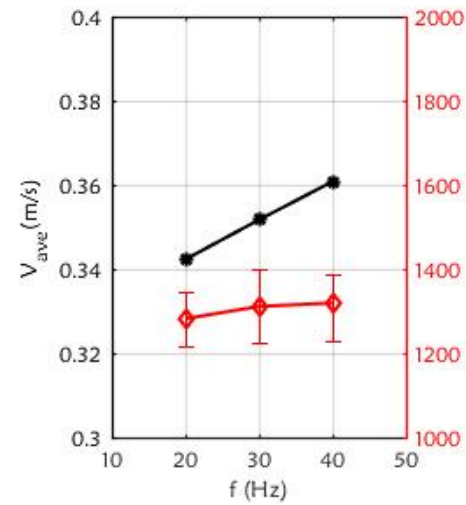

(a) $A=5.0 \mu \mathrm{m}$

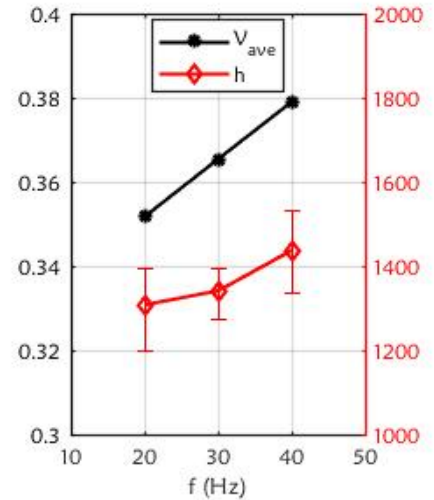

(b) $A=7.5 \mu \mathrm{m}$

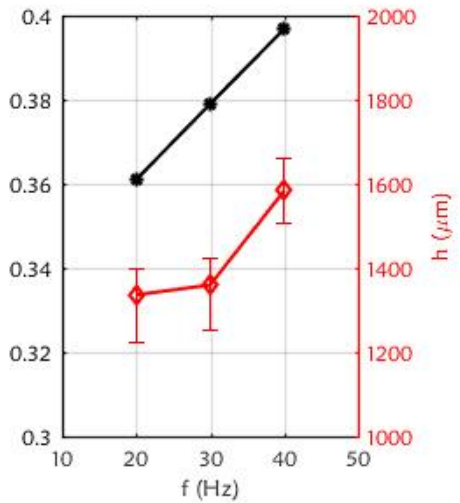

(c) $A=10.0 \mu \mathrm{m}$

Figure 9: Effect of vibration frequency on average flushing speed and machining

The effects of vibration frequency on average flushing speed and machining depth are illustrated in Figure 9. At every vibration amplitude $(5,7.5$, and $10 \mu \mathrm{m})$, a higher vibration frequency leads to faster average flushing speed and deeper machining depth. When vibration frequency increases from 20 to $40 \mathrm{~Hz}$, the average flushing speeds increase by $5.4 \%(0.3423-0.3608 \mathrm{~m} / \mathrm{s}), 7.8 \%(0.3517-0.3790 \mathrm{~m} / \mathrm{s})$ and $9.9 \%(0.3610-0.3968 \mathrm{~m} / \mathrm{s})$, at respective vibration amplitude. Improving of flushing speed changes machining depths by $2.9 \%$ (1282-1319 $\mu \mathrm{m}), 9.9 \%(1308$ $1437 \mu \mathrm{m})$ and $18.6 \%(1336-1584 \mu \mathrm{m})$, respectively.

The relationship between average flushing speed and machining depth is shown in Figure 10. Due to the limitation of power supply to the vibration system, the input current can be adjusted up to $7 \mathrm{~A}$ at frequency $<40 \mathrm{~Hz}$ with fixed $10 \mu \mathrm{m}$ amplitude. This maximum current of $7 \mathrm{~A}$ must be maintained at frequency higher than $40 \mathrm{~Hz}$ with adjustable amplitudes. Simulation for frequency below and above $40 \mathrm{~Hz}$ shows the peak flushing average at $40 \mathrm{~Hz}$ while similar trend is seen for the hole depth data. There is a clear correlation between average flushing speed and machining depth.

Low frequency vibration of workpiece enhances flushing speed, enhances ion transport rate and leads to more effective machining rate. Similar results were also reported by other researchers [2] who observed that:

- At any vibration amplitude $(4,6$, and $8 \mu \mathrm{m})$, the $M R R$ increased when increasing vibration frequency from 0 to $50 \mathrm{~Hz}$. However, the $M R R$ dropped when increasing frequency further to $200 \mathrm{~Hz}$.

- At any vibration frequency $(50$ and $100 \mathrm{~Hz}$ ), the $M R R$ increased with increasing vibration amplitude in the range $0-8 \mu \mathrm{m}$. The maximum $M R R$ was obtained when vibrating at $8 \mu \mathrm{m}$ amplitude for any vibration frequency. 
The maximum machining depth, therefore highest $M R R$, in this study is when vibrating a workpiece at $40 \mathrm{~Hz}$ compared to $50 \mathrm{~Hz}$ in other study [2]. The simulation study indicates that a higher flushing speed is expected at lower frequency (Figure 5), therefore, a lower frequency with larger vibration amplitude could lead to optimal MRR. The upper bound for increasing vibration amplitude is the critical inter-electrode distance at which damaging sparks would occur due to electrical discharging. The trends from simulation and experimental data can be explained.

- At either higher vibration frequency or vibration amplitude, more ions and by-products particles starting at the workpiece surface would be pushed toward the advancing electrode in the first half cycle, when the workpiece is reversed during the second half cycle, theses ions and particles -- physically are away from the solid workpiece surface -- are subjected to higher shear and swept away in the electrolyte flow.

- When ions and by-products are effectively swept away from the workpiece surface, fresh electrolyte can be replenished to accelerate the electrochemical reactions (equations 1-4) and result in a deeper hole and a faster removal rate.

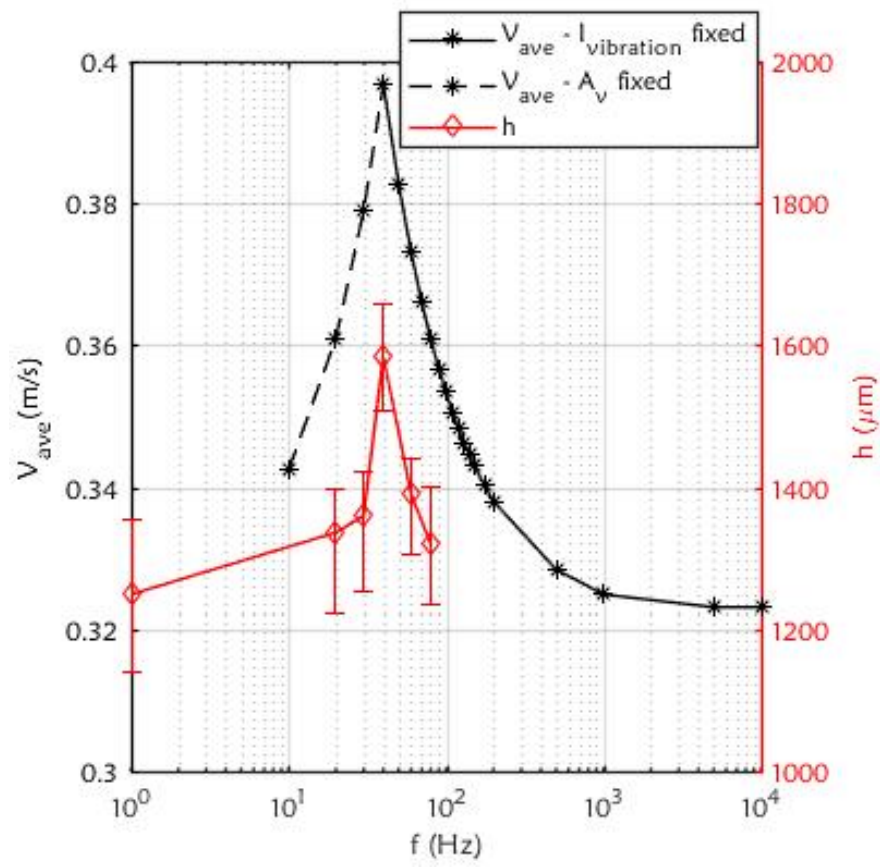

Figure 10: Relationship between average flushing speed and machining depth

\subsubsection{Taper Angles}

The effects of vibration amplitude on average flushing speed and taper angle are illustrated in Figure 11. At every vibration frequency $(20,30$, and $40 \mathrm{~Hz})$, a higher vibration amplitude leads to faster flushing speed and smaller taper angle - therefore, straighter and sharper hole profile. When vibration amplitude increases from 5.0 to $10.0 \mu \mathrm{m}$, the taper angles decreases by $8.7 \%\left(31.92-29.15^{\circ}\right), 12.8 \%\left(29.32-25.56^{\circ}\right)$ and $43.4 \%\left(29.28-16.57^{\circ}\right)$, at respective vibration frequency.

The effects of vibration frequency on average flushing speed and taper angle are illustrated in Figure 12. At every vibration amplitude $(5,7.5$, and $10 \mu \mathrm{m})$, a higher vibration frequency leads to a smaller taper angle. When vibration frequency increases from 20 to $40 \mathrm{~Hz}$, the taper angles decreases by 3.4\% (31.92-29.28 $), 27.3 \%\left(29.81-21.67^{\circ}\right)$ and $43.2 \%\left(29.15-16.57^{\circ}\right)$ at corresponding vibration amplitude.

Simulation and experimental data suggest a negative correlation between average flushing speed and taper angle (Figure 15). Authors from a different study [16] reported a similar trend on hole shape after ECM; the conicity (slope of a cone) decreased from 3.95 to $3.25 \%$ when vibration amplitude increased from 20 to $100 \mu \mathrm{m}$. This trend can also be explained qualitatively:

- Vibration of workpiece leads to a higher flushing speed that breaks up agglomerated groups of by-products into smaller chunks of particles.

- The smaller chunks forming between electrodes then travel up the wall of hole and out (Figure 6). The smaller coalesced particles would erode the wall less and result in smaller taper angle and sharper hole profile. 


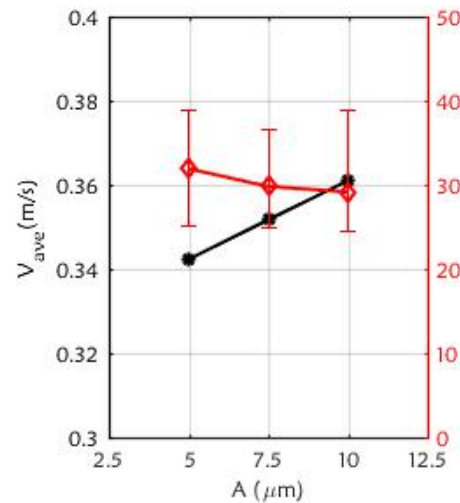

(a) $f=20 \mathrm{~Hz}$

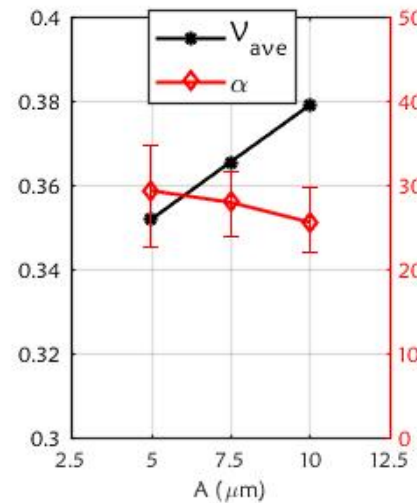

(b) $f=30 \mathrm{~Hz}$

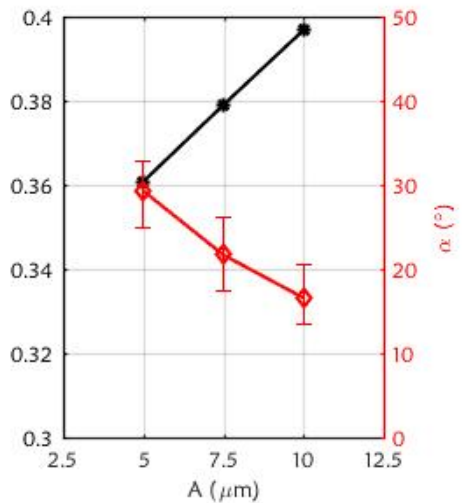

(c) $f=40 \mathrm{~Hz}$

Figure 11: Effect of vibration amplitude on average flushing speed and taper angle

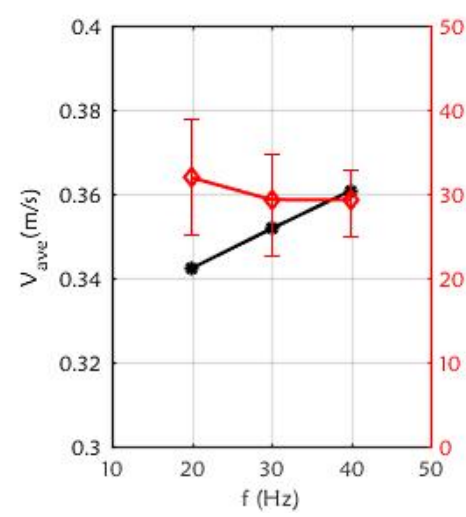

(a) $A=5.0 \mu \mathrm{m}$

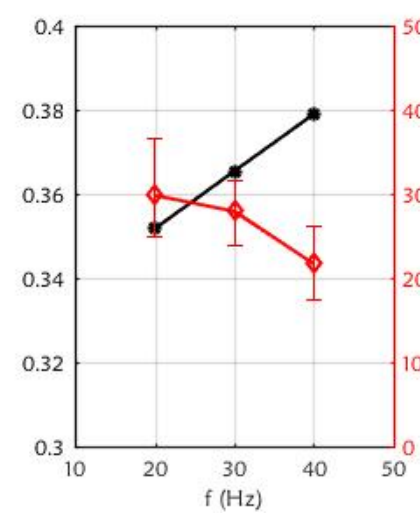

(b) $A=7.5 \mu \mathrm{m}$

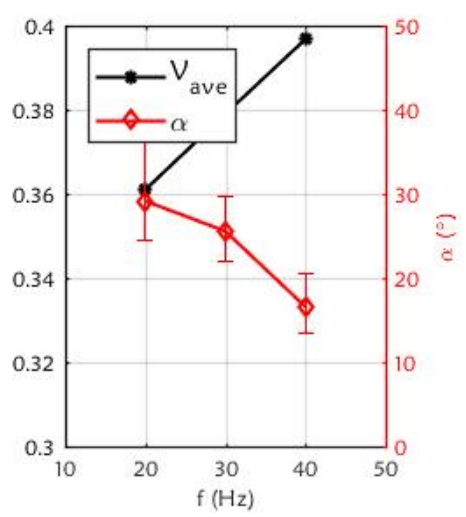

(c) $A=10.0 \mu \mathrm{m}$

Figure 12: Effect of vibration frequency on average flushing speed and taper angle

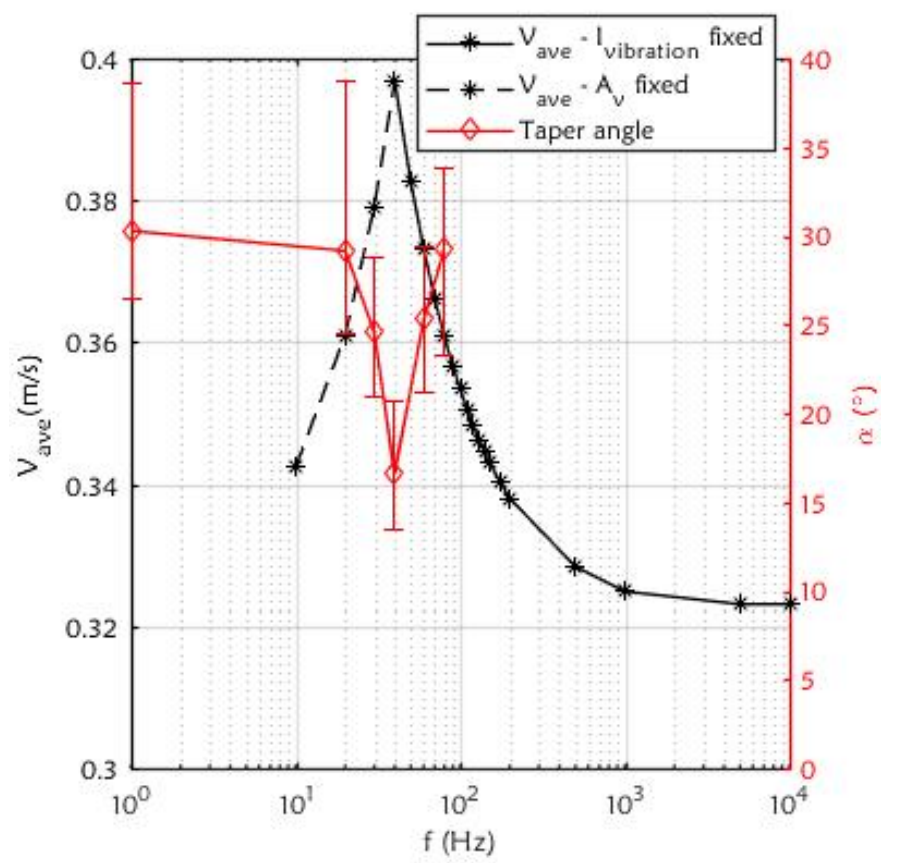

Figure 13: Relationship between average flushing speed and hole taper angle. 


\section{CONCLUSIONS AND RECOMMENDATIONS}

This research simulates how the ion hydroxide by-product being flushing away in electrochemical machining. Simulation results and experimental data for ECM'ing 1018 steel with pulsed current and low frequency vibration were performed on a horizontal ECM system. The paper shows that:

1) Iron hydroxide particle with an average size of $\varnothing 2 \mu \mathrm{m}$ was the resulted by-product.

2) Simulation of the motion of a single particle using computational fluid dynamic is performed to track the particle motion and speed between electrodes. Flushing of by-products is characterized by calculating of particle flushing speed when it exits inter-electrode gap. The optimal flushing speed of $\sim 0.4 \mathrm{~m} / \mathrm{s}$ was calculated for workpiece vibration frequency of $40 \mathrm{~Hz}$ at $10 \mu \mathrm{m}$ vibration amplitude.

3) Simulation results suggest that a higher flushing speed can be obtained below $40 \mathrm{~Hz}$ if vibrating amplitude larger than $10 \mu \mathrm{m}$ is possible without initiating damaging sparks.

4) Experimental results suggest high flushing speed of by-product leads to deeper and sharper ECM profiles. More particles are pushed away from the workpiece surface during the first half of a vibrating cycle, and they are swept away by electrolyte flow during the cycle's second half.

Future works should (i) explore the effect of vibration at lower than $40 \mathrm{~Hz}$ yet at higher vibration amplitude without initiating sparks, and (ii) extend the simulation to study the interaction of multiple particles in the inter-electrode gap.

\section{ACKNOWLEDGEMENT}

This research work was support with grant \#1745678 from CONACyT (Mexico); and grants \#512433, \#2847 from Agilent University Research Corporation (USA).

\section{REFERENCES}

1. McGeough, J. A. (1974). Principles of electrochemical machining. London: Chapman and Hall.

2. Liu, Z., Zhang, H., Chen, H., \& Zeng, Y. (2013). Investigation of Material Removal Rate in Micro Electrochemical Machining with Lower Frequency Vibration on Workpiece. International Journal of Machining and Machinability of Materials, 14(1), 91-104.

3. Acharya, B. R., Mohanty, C. P., \& Mahapatra, S. S. (2013). Multi-objective Optimization of Electrochemical Machining of Hardened Steel Using NSCAll. Procedia Engineering, 51, 554-560.

4. Senthilkumar, C., Ganesan, G., \& Karthikeyan, R. (2013). Influence of Input Parameters on Characteristics of Electro Chemical Machining Process International Journal of Applied Science and Engineering, 11(1), 13-24.

5. Bhattacharyya, B., \& Sorkhel, S. K. (1999). Investigation for controlled ellectrochemical machining through response surface methodology-based approach. Journal of Materials Processing Technology, 86(1-3), 200-207.

6. Senthilkumar, C., Ganesan, G., Karthikeyan, R., \& Srikanth, S. (2010). Modelling and analysis of electrochemical machining of cast Al/20\%SiCp composites. Materials Science and Technology, 26(3), 289-296.

7. Schuster, R., Kirchner, V., Allongue, P., \& Ertl, G. (2000). Electrochemical Micromachining. Science, 289(5476), 98-101.

8. Feng, Z., Granda, E., \& Hung, W. (2016). Experimental Investigation of Vibration-Assisted Pulsed Electrochemical Machining. Procedia Manufacturing, 5, 798-814.

9. Bhattacharyya, B., \& Munda, J. (2003). Experimental Investigation on the Influence of Electrochemical Machining Parameters on Machining Rate and Accuracy in Micromachining Domain. International Journal of Machine Tools and Manufacture, 43(13), 1301-1310.

10. Munda, J., \& Bhattacharyya, B. (2008). Investigation Into Electrochemical Micromachining (EMM) Through Response Surface Methodology Based Approach. The International Journal of Advanced Manufacturing Technology, 35(7-8), 821-832.

11. Senthilkumar, C., Ganesan, G., \& Karthikeyan, R. (2012). ECM of Al/15\% SiCP Composites Through a Response Surface Methology-Based Approach. International Journal of Materials Research, 103, 378-382.

12. Ruszaj, A., Zybura-Skrabalak, M., Skoczypiec, S., \& Żurek, R. (2001). Electrochemical machining supported by electrode ultrasonic vibrations. Paper presented at the 13th International Symposium for Electromachining, ISEM, Spain, May.

13. Nicoară, D., Hedeş, A., \& Şora, I. (2006). Ultrasonic enhancement of an electrochemical machining process. Paper presented at the Proceedings of the 5th WSEAS international conference on Applications of electrical engineering.

14. Patel, J. B., Feng, Z., Villanueva, P., \& Hung, W. N. P. (2017). Quality enhancement with ultrasonic wave and pulsed current electrochemical machining. Procedia Manufacturing, 10, 662-673.

15. Ghoshal, B., \& Bhattacharyya, B. (2015). Vibration assisted electrochemical micromachining of high aspect ratio micro features. Precision Engineering, 42, 231-241.

16. Ebeid, S. J., Hewidy, M. S., El-Taweel, T. A., \& Youssef, A. H. (2004). Towards Higher Accuracy for ECM Hybridized with Low-Frequency Vibrations Using the Response Surface Methodology. Journal of Materials Processing Technology, 149(1-3), 432-438. 
17. Bhattacharyya, B., Malapati, M., Munda, J., \& Sarkar, A. (2007). Influence of Tool Vibration on Machining Performance in Electrochemical Micro-Machining of Copper. International Journal of Machine Tools and Manufacture, 47(2), 335-342.

18. Rebschläger, A., Kollmannsperger, R., \& Bähre, D. (2014). Video based Process Observations of the Pulse Electrochemical Machining Process at High Current Densities and Small Gaps. Procedia CIRP, 14, 418-423.

19. Retrieved from http://www.velmex.com/Products/XSlide/XSlide-motorized.html.

20. Kothandaraman, C., \& Subramanyan, S. (2013). Heat and Mass Transfer Data Book (8th Edition ed.): New Academic Science.

21. Retrieved from http://www.nde-ed.org.

22. Serway, R., \& Jewett, J. (2013). Physics for scientists and engineers with modern physics: Nelson Education.

23. Gosman, A., \& Loannides, E. (1983). Aspects of computer simulation of liquid-fueled combustors. Journal of Energy, 7(6), 482-490.

24. Anderson, T., \& Jackson, R. (1968). A fluid mechanical description of fluidized beds: Stability of the uniform state of fluidization. I\&EC Fundamentals, 7, 12-21. 


\section{Appendix}

\section{Modeling of Particle Flow}

This appendix details steps to simulate a particle flow between electrodes in Electrochemical Machining (ECM). Formulas are provided for computational fluid dynamic simulation using ANSYS Fluent software. Referring to Figures 2 and 3, it is assumed that:

- The simulation is simplified to a 2-dimension problem.

- The simulation location is the top most part of the horizontal ECM electrode-workpiece area.

- The iron hydroxide ECM by-product is assumed to be a spherical particle with $\varnothing 2 \mu$ m diameter.

- There is no interaction among particles.

- Although the electrolyte flow affects the particle, there is negligible effect of the particle to electrolyte flow.

For any particle-fluid flow system the dynamic of fluid flow is characterized by (i) the solution of Navier-Stokes equation for continuum fluid (primary phase), (ii) the solution of Newton equation of motion for discrete particles (second phase), and (iii) initial and boundary conditions. In this investigation the Computational Fluid Dynamics Discrete Element Method (CFD-DEM) was used to capture the motion of discrete particles. In CFD-DEM coupling technique, the flow of primary phase (fluid) was determined by the CFD and the motion of second phase (particles) was obtained by solving Newton equations of motion on a computational cell scale.

For particle-fluid flow system a particle can have translational and rotational motion. During its movement, the particle may interact with its neighboring particles or walls and interact with its surrounding fluid, through which the momentum and energy are exchanged. Such movement is not only by the forces and torques originated from its immediately neighboring particles and vicinal fluid, but is also affected by particles and fluids far away through the propagation of disturbance waves. In the DEM approach, we introduce a numerical time step which less than a critical value so that disturbance cannot propagate from the particle and fluid farther than its immediate neighboring particles and vicinal fluid. For a coarse particle system, all the resultant forces on a particle can be determined exclusively from its interaction with the contacting particles and vicinal fluid. However, for a fine particle system, non-contact forces, such as van der Waals and electrostatic forces are also considered.

Since a particle is assumed to be spherical, only translational movement of the particle is considered in this study. The translational motion of discrete particles $i$ with mass $m_{i}$ follows Newton $2^{\text {nd }}$ law:

$$
m_{i} \frac{d \overrightarrow{v_{l}}}{d t}=\sum_{j} \overrightarrow{F_{l J}^{c}}+\sum_{k} \overrightarrow{F_{l k}^{n c}}+\overrightarrow{F_{l}^{f}}+\overrightarrow{F_{l}^{g}}
$$

Where; $m_{i}=$ mass of particle $\mathrm{i}, \overrightarrow{v_{l}}$ : translational velocity of particle $i, \overrightarrow{F_{l}}$ : contact force acting on particle $i$ by particle $j, \overrightarrow{F_{l k}^{n c}}$ : noncontact force acting on particle $i$ by particle $k$ or other sources, $\overrightarrow{F_{l}^{f}}$ : particle-fluid interaction force on particle $i$, and $\overrightarrow{F_{l}^{g}}$ : gravitational force.

Non-contact forces, such as van der Waals force and capillary force, can be neglected since they have little influence on the flushing time. Therefore, equation (A1) can be simplified to:

$$
m_{i} \frac{d \overrightarrow{v_{l}}}{d t}=\overrightarrow{F_{l}^{f}}+\overrightarrow{F_{l}^{g}}
$$

The surrounding fluid will interact with particle by generating various particle-fluid interaction forces (drag force), in addition to the buoyance force. For a single spherical particle in a fluid, the equation to determine the drag resistance force was derived to be [23]:

With

$$
\overrightarrow{F_{l}^{f}}=\overrightarrow{F_{d}}+\overrightarrow{F_{b}}=m_{i} \frac{\overrightarrow{v_{F}}-\overrightarrow{v_{p}}}{\tau_{r}}-V_{i} \rho \vec{g}
$$

$$
\begin{gathered}
\tau_{r}=\frac{\rho_{p} d_{p}^{2}}{18} \frac{24}{C_{d} R_{e}} \\
R_{e} \equiv \frac{\rho d_{p}\left|\vec{u}_{p}-\vec{u}\right|}{\mu}
\end{gathered}
$$


Where; $\tau_{r}=$ particle relaxation time, $\overrightarrow{F_{d}}=$ drag force, $\overrightarrow{F_{b}}$ : buoyance force, $\overrightarrow{v_{F}}=$ fluid phase velocity, $\overrightarrow{v_{p}}=$ particle velocity, $V_{i}$ : particle volume, $\rho$ : fluid density, $\mu$ : molecular viscosity of the fluid, $\rho_{p}$ : particle density, $d_{p}=$ particle diameter, and $R_{e}=$ relative Reynold number.

By combining equations ( $\mathrm{A} 2$ - A3), the equation for particle motion becomes:

$$
\frac{d \overrightarrow{v_{l}}}{d t}=\frac{\overrightarrow{v_{F}}-\overrightarrow{v_{p}}}{\tau_{r}}+\frac{\vec{g}\left(\rho_{p}-\rho\right)}{\rho_{p}}
$$

During an iteration step in simulation, the source terms applied to the continuous phase equation to the new values are:

$$
\begin{gathered}
F_{\text {new }}=F_{\text {old }}+\alpha\left(F_{\text {calculated }}-F_{\text {old }}\right) \\
Q_{\text {new }}=Q_{\text {old }}+\alpha\left(Q_{\text {calculated }}-Q_{\text {old }}\right) \\
M_{\text {new }}=M_{\text {old }}+\alpha\left(M_{\text {calculated }}-M_{\text {old }}\right)
\end{gathered}
$$

Where; $\alpha=$ under-relaxation factor for particles, default value is 0.9 for transient flow simulation with unsteady particle tracking, otherwise $\alpha$ is $0.5, F=$ force, $Q=$ energy, and $M=$ momentum.

For fluid phase, the governing equations derived from Navier-Stoke equation comply with the law of conservation of mass and momentum in terms of local-average variables [24]:

$$
\begin{gathered}
\frac{\partial \varepsilon_{f}}{\partial t}+\nabla \cdot \varepsilon_{f} \vec{u}_{f}=0 \\
\frac{\partial\left(\rho_{f} \varepsilon_{f} \vec{u}_{f}\right)}{\partial t}+\nabla \cdot\left(\rho_{f} \varepsilon_{f} \vec{u}_{f} \vec{u}_{f}\right)=-\varepsilon_{f} \nabla p-\overrightarrow{F_{P-F}}+\nabla \cdot\left(\varepsilon_{f} \tau\right)+\rho_{f} \varepsilon_{f} \vec{g}
\end{gathered}
$$

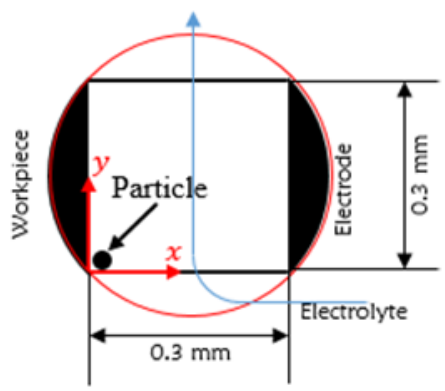

Figure A1. Simulation boundaries.

Figure A1, part of Figure 3 in the main text, shows the simulation boundaries. A spherical particle P starts at the lower left corner of the two-dimensional $0.3 \mathrm{~mm} \times 0.3 \mathrm{~mm}$ simulation area. The vibration of the workpiece (governed by vibration frequency and amplitude) alters the position of this particle. The flow chart in Figure A2 show how position and velocity of the particle $\mathrm{P}$ are calculated. After each iteration, the position $y_{p}$ of the particle is compared against the vertical boundary; when the particle exits the vertical boundary $\left(y_{p}>0.3 \mathrm{~mm}\right)$ then the simulation would end. 


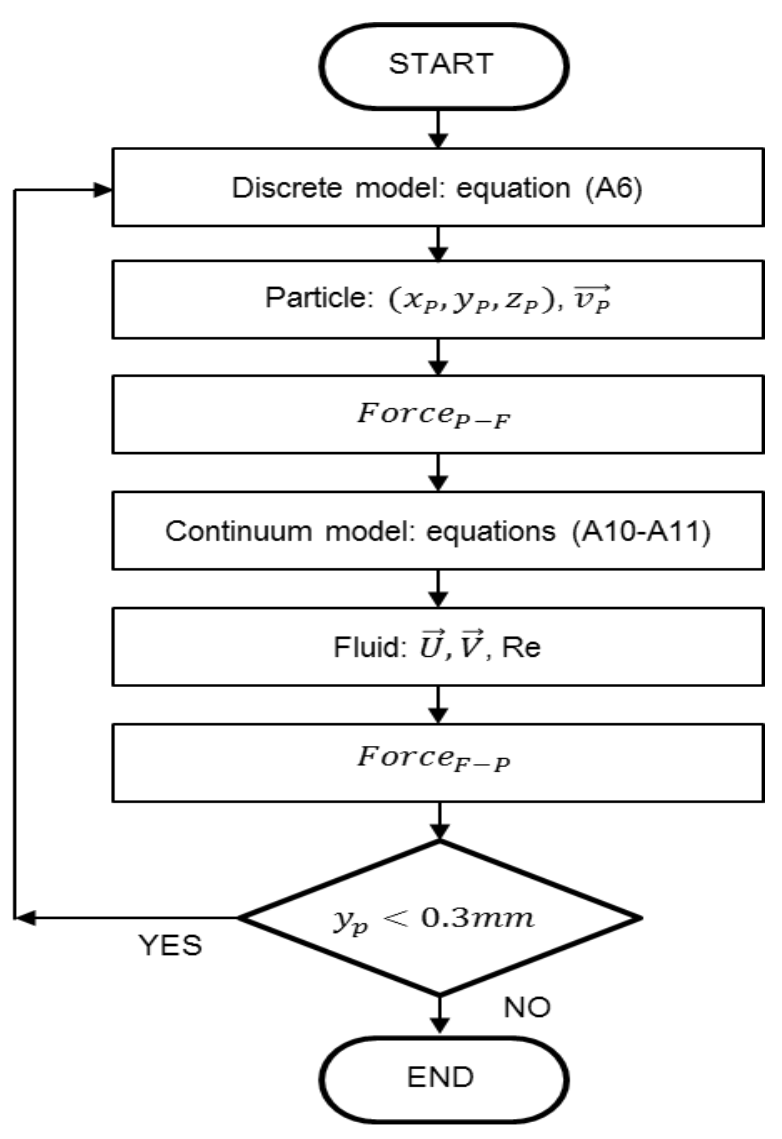

Figure A2 Flow chart of simulation 